\title{
Aby Warburg em português
}

Lenin Bicudo BÁrbara - Universidade de São Paulo

Em 2013, a editora Contraponto publicou de uma só vez uma trinca de livros relacionados ao historiador da arte alemão Aby Moritz Warburg (1866-1929), com destaque para a tradução da coletânea que compila seus textos publicados ainda em vida. São eles: A renovação da Antiguidade pagã - Contribuições científico-culturais para a história do Renascimento europeu, de Aby Warburg; Warburg e a imagem em movimento, de Philippe-Alain Michaud; A imagem sobrevivente: história da arte e tempo dos fantasmas segundo Aby Warburg, de Georges Didi-Huberman.

Warburg nasceu em Hamburgo, como primogênito de uma família de banqueiros. Ainda que não tenha se envolvido pessoalmente nos negócios, estes foram decisivos para sua formação, pois lhe permitiram montar uma biblioteca que mais tarde se tornaria um renomado instituto de pesquisa - o Instituto Warburg, ligado à Universidade de Hamburgo -, frequentado na época por historiadores da arte de primeira linha, como Erwin Panofsky, Edgar Wind, e Fritz Saxl, sem mencionar filósofos como Ernst 
Cassirer ${ }^{1}$. Essa circunstância proporcionou a Warburg grande independência para a pesquisa, que ele conseguiu traduzir em um método peculiar e inovador de análise iconográfica, muito bem adaptado à pesquisa interdisciplinar.

Até recentemente, o acesso do público brasileiro à obra de Warburg era bastante restrito: só era possível consultá-la no idioma original ou por meio de traduções para outras línguas² ${ }^{2}$. Em português, dispúnhamos apenas de uns poucos textos esparsos, publicados em periódicos nacionais, traduzidos a partir de outras traduções ${ }^{3}$; além disso, em 2012 foi publicada em Portugual uma tradução direta para o primeiro trabalho de destaque de Warburg ${ }^{4}$. Essa longa e indevida carência de traduções para o português foi finalmente sanada com a publicação d'A renovação da Antiguidade pagãa, traduzida diretamente do alemão por Markus Hediger.

Deve-se ter em mente que $A$ renovação da Antiguidade pagã não é uma coletânea qualquer, mas sim uma edição crítica dos escritos reunidos de Warburg. A coletânea, originalmente publicada em 1932, foi a princípio pensada como primeiro passo

\footnotetext{
${ }^{1}$ Outros, como Ernst Gombrich, Arnaldo Momigliano e Michael Baxandall se envolveriam com o Instituto em Londres, cidade para onde foi transferido em 1934, por ocasião da ascensão do Nazismo.

${ }^{2}$ Ver por exemplo The Renewal of Pagan Antiquity, introdução de Kurt W. Forster, tradução David Britt; Los Angeles: The Getty Research Institute, 1999; Essais Florentins, introdução de Eveline Pinto, tradução Sybilline Muller, Paris: Klicksieck, 2003.

${ }^{3}$ Tenho conhecimento destes dois textos: Aby Warburg, 2005, "Imagens da região dos índios Pueblo da América do Norte", em: Concinnitas, ano 6, v. 1: Rio de Janeiro, pp. 9-29; e Aby Warburg, 2009, "Mnemosyne", em: Arte Ensaios, v. 19: Rio de Janeiro, pp. 125-131.

${ }^{4}$ Cf. Aby Warburg, 2012, Sandro Botticelli: o Nascimento de Vénus e a Primavera, Lisboa: KKYM. Não tive acesso ao livro; outra tradução do mesmo texto está contida em $A$ renovação da Antiguidade pagã.
} 
de um projeto editorial que visava a publicação das obras reunidas de Warburg, tal como concebera Fritz Saxl, importante colaborador de Warburg e peça-chave na história do Instituto. Quem assina a edição dessa primeira parte, a única publicada por seus idealizadores originais, é Gertrud Bing (também assistente e mais tarde diretora do Instituto Warburg), em colaboração com Fritz Rougemont. O mesmo volume seria reimpresso em 1998, ganhando uma segunda apresentação. Essa reedição foi concebida visando a retomada e reformulação do projeto de publicação dos espólios de Warburg - projeto hoje em curso, com outros volumes já publicados ou em preparação ${ }^{5}$.

O objetivo declarado do volume ora traduzido para o português é reunir todos os textos publicados em vida por Warburg. São ao todo 37 textos, em sua maior parte acompanhados de imagens; além disso, a edição brasileira traz a apresentação do volume original e a da reedição de 1998, junto com todo o aparato crítico da edição alemã, que comentarei adiante.

Como o critério para a seleção dos textos é bem geral, temos uma coletânea bem diversificada, com textos de importância igualmente diversa: ao lado de textos mais longos, densos e trabalhados (tais como o estudo sobre os afrescos do Palazzo Schifanoia, que discutiremos em maior detalhe), há também uma série de publicações mais breves, boa parte das quais são de interesse apenas documental, e que amiúde não passam de resumos para alguma palestra mais elaborada (como é o caso de "A emergência do estilo ideal à antiga na pintura do início do

\footnotetext{
${ }^{5}$ Para mais detalhes sobre o volume original e a reedição de 1998, bem como para a discussão das dificuldades envolvidas na edição dos espólios warburguianos, cf. Warburg, 2013, A renovação da Antiguidade pagã Contribuições científico-culturais para a história do Renascimento europeu. Contraponto: Rio de Janeiro, pp. xxii-xxxiv.
} 
Renascimento", de 1914).

Antes de tratar do conteúdo dos textos, convém comentar rapidamente o volumoso aparato crítico que acompanha a edição. Ele é composto por uma série de adendos, acrescentados ao fim de cada texto. Esses adendos contêm: reproduções das anotações feitas por Warburg em seus exemplares pessoais; intervenções dos editores alemães e de seus colaboradores, que na maior parte das vezes apenas destrincham as referidas anotações; e conteúdo documental de apoio. Embora a maior parte das intervenções se baseie nas anotações do próprio Warburg, há ainda uma série de acréscimos dos próprios editores. Esse é o caso sobretudo dos adendos aos textos "Os figurinos teatrais para os intermezzi de 1589" e "A arte italiana e a astrologia internacional no Palazzo Schifanoia, em Ferrara" - em que boa parte do material de apoio é na verdade fruto do trabalho dos editores e de seus colaboradores.

$$
* * *
$$

Os primeiros textos da coletânea datam da década de 1890, e são em geral focados no estudo da cultura da alta sociedade florentina. Dentre eles, destacam-se "O nascimento de Vênus e A Primavera de Sandro Botticelli" e "Os figurinos teatrais para os Intermezzi de 1589". Esses dois estudos sobre a cultura florentina permitem caracterizar a estratégia expositiva por ele adotada na maior parte dos seus escritos mais elaborados. Warburg quase sempre parte de um conjunto bem delimitado de obras de arte e registros históricos, que em seguida submete a uma cuidadosa análise iconográfica, de que se servirá para propor uma interpretação mais geral acerca de alguma transformação sofrida pela cultura europeia. 
No primeiro texto, o ponto de partida são as duas famosas pinturas mitológicas feitas por Botticelli por encomenda dos Medici. O método adotado por Warburg consiste basicamente em compará-las com outras obras ou produtos culturais que circulavam na alta sociedade italiana de então, visando, de um lado, mapear as fontes antigas utilizadas para compor as figuras representadas nessas pinturas e, de outro, identificar os indivíduos e círculos sociais diretamente envolvidos nessa composição. Warburg mostra em detalhes, por exemplo, como a cena da perseguição de Zéfiro a Flora em "A Primavera" (ou "O Reino de Vênus", como Warburg prefere) reconstrói de modo fiel a narrativa de Ovídio, e como o tropo da perseguição erótica estava bem presente no imaginário italiano da época (Warburg, 2013, pp. 33-38). O levantamento das fontes eruditas deixa claro que o humanista italiano Angelo Poliziano, que possuía fortes vínculos com os Medici ${ }^{6}$, desempenhara um papel decisivo como inspirador da obra.

Mas todo o minucioso levantamento iconográfico é mobilizado com vistas a um objetivo ainda mais geral: abrir espaço para uma interpretação nuançada e abrangente da influência da Antiguidade durante o Renascimento, rompendo com a visão classicizante que a reduzia à postura da "grandiosidade serena" (Cf. Ibid., p. 53). Pois o que Warburg mostra, passo a passo, é como, nos inícios do Renascimento, buscava-se os temas e modelos vindos da Antiguidade justamente para lidar com o problema da representação da vida em movimento - que, nesse caso, tentou-se resolver conferindo um movimento ostensivo aos motivos acessórios, tais como os cabelos e as roupas ${ }^{7}$.

\footnotetext{
${ }^{6}$ Ele foi, p. ex., tutor dos filhos de Lorenzo de Medici.

${ }^{7}$ Daí a predileção especial de Poliziano por Ovídio, que fornecia vivas
} 
O outro texto que mencionei da década de 1890 é em boa parte dedicado à reconstrução detalhada de certos espetáculos teatrais e musicais - os intermezzi - encenados em maio de 1589, em Florença, como parte de uma série de festividades em torno do casamento do Grão-duque Ferdinando I de Medici com Christina de Lorena. Tais espetáculos foram produzidos com grande pompa, contando inclusive com artifícios cênicos que impressionaram os espectadores da época, como, por exemplo, a encenação da luta de Apolo com o dragão. Baseado na ampla documentação de que dispunha, Warburg mostra como a ornamentação dos figurinos foi pensada como reconstrução fiel e detalhada de modelos da Antiguidade - e como justamente o excesso de detalhes, comunicados de forma "muda" pelos ornamentos, tornou o seu intrincado simbolismo ininteligível para o público. Também nesse caso, Warburg sugere tratar-se de uma restituição seletiva da Antiguidade: para ele, as "origens verdadeiras do intermezzo" remontariam à "arte pantomímica da procissão mitológica", e esta, por sua vez, explicaria a atenção especial concedida à ornamentação do figurino (Cf. Ibid., pp. 358-359). Como resultado desse princípio seletivo, teríamos uma reconstituição muito fiel em termos formais à Antiguidade mas que estava fadada a não ser captada pelo público. Em face disso, Warburg sugere que esse enfoque mais formalista seria refinado e substituído por um enfoque mais "sentimental" dos temas da Antiguidade, tal como o que caracterizaria peças como a Daphne, encenada em Florença poucos anos depois dos intermezzi, e considerada a primeira ópera moderna. Essa inflexão estilística é descrita por Warburg nos seguintes termos:

Nada caracteriza melhor a transformação do gosto dos descrições desses elementos. 
inventores e do público do que uma comparação entre Daphne de 1594 e o terceiro intermezzo de 1589; a luta com o dragão é reduzida a um breve prólogo, no qual, porém [...] ainda podem ser detectados traços nítidos do espetáculo de 1589 [...]. Mas a ambição arqueológica de executar a dança segundo as regras de Julius Pólux não domina mais a psicologia de Apolo [...]. O antigo símbolo cósmico de 1565 e o dançarino mudo transformaram-se aos poucos num jovem deus sentimental que não só encontrou a fala, mas também melodias até então nunca ouvidas, a velha canção do poder do amor, do pastor apaixonado e da pastora tímida. (Warburg, 2013, p. 374)

Assim, vemos em ambos os textos como um estudo de caso de escopo bem delimitado desemboca numa interpretação mais geral de algum momento de inflexão estilística decisivo para o curso da cultura europeia - indicando a presença de diversas concepções "concorrentes" da Antiguidade, que variam de acordo com o contexto presente no qual a obra é concebida. Nesses estudos em particular, o contexto é ainda restrito a certos aspectos e eventos marcantes da sociedade florentina no momento a cada vez posto em foco - o que marca uma diferença importante em relação aos estudos da década seguinte.

Os textos de 1900 em diante trazem uma novidade decisiva: tratam cada vez mais da questão do intercâmbio dos modelos expressivos no território europeu. Esse é o caso, por exemplo, do texto de 1902 sobre a relação entre as culturas florentina e flamenga, e do breve, porém denso estudo de 1905 sobre Dürer, em que Warburg discorre sobre a circulação de certos modelos 
expressivos entre a Itália e a Alemanha ${ }^{8}$.

Ao lado dessa ampliação "territorial", percebe-se ainda um interesse crescente na produção cultural num sentido mais amplo - ou seja, não apenas nas obras de artistas mais eminentes. É verdade que já no primeiro trabalho de Warburg percebese uma tendência a considerar formas artísticas menos notadas, tais como arcas de casamento e medalhões. Mas a análise desses objetos era mais um instrumento para a identificação das fontes que informaram a composição de obras "maiores", no caso as pinturas de Botticelli ${ }^{9}$. Nos textos seguintes, a análise incide diretamente sobre formas artísticas como a gravura ${ }^{10}$ e a tapeçaria $^{11}$.

\footnotetext{
${ }^{8} \mathrm{~A}$ relação entre as culturas germânica e italiana foi muito cara a Warburg, cuja família era de origem italiana.

${ }^{9} \mathrm{O}$ que é, aliás, uma resposta consequente, diante das características do pintor que servia o público florentino: "O público burguês por volta de 1470 vê o artista como o artesão produtor de objetos que, nascido sob o signo do planeta Mercúrio, tudo pode e tem; nos fundos de sua oficina, pinta e esculpe, mas, lá na frente, na loja, vende produtos para todas as necessidades cotidianas: fivelas de cinto, baús de casamento decorados, utensílios para o clérigo, voti de cera e gravuras. Ninguém procura o artista abstrato em seu ateliê para compartir com ele, numa atitude estética de empatia artística à luz da aurora boreal, os sentimentos dissonantes do fatigado homem de cultura, mas chama o ourives e o pintor para que saiam da sua oficina para a realidade do dia e usem sua própria existência para criar algum elemento do ciclo da vida: uma construção, uma joia, alguma ferramenta ou uma procissão festivamente ordenada". (Warburg, 2013, p. 139).

${ }^{10} \mathrm{E}$ o caso do estudo sobre Dürer e de "Sobre as imprese amorose nas gravuras florentinas antigas", também de 1905.

${ }^{11}$ Dessa época, chamo a atenção para a breve exposição de 1907, com o título "Trabalhadores campestres em tapetes da Borgonha". Os tapetes flamengos seriam tema de outros dois textos igualmente breves, que apareceriam só depois: "Aeronave e submergível no imaginário medieval", de 1913; e "As festas mediceias na corte dos Valois em tapetes flamengos da Galleria degli Uffizi", de 1927.
} 
Essa ênfase está intimamente ligada à ampliação territorial da análise warburguiana, agora mobilizada para acompanhar a perambulação das imagens e ideias vindas da Antiguidade pela Europa, o que exige, justamente, um enfoque nos seus veículos, dos quais o mais óbvio é a gravura ${ }^{12}$.

Graças a essa abordagem, Warburg é capaz de expor uma visão não só bastante nuançada sobre o Renascimento europeu, apontando de modo incisivo para a enorme variedade de formas com que se buscou tornar presente este ou aquele aspecto da Antiguidade em cada ambiente social específico, como, além disso, bastante coesa, já que toda essa variedade é concebida como uma série de diferentes ramificações de um processo contínuo de desenvolvimento do estilo, dotado de dimensões espaciais e temporais bem concretas. Nada indica mais claramente a importância que o problema da circulação da produção cultural tinha para a visão warburguiana do Renascimento europeu, do que sua caracterização deste como a "era da migração internacional das imagens"13 (Warburg, 2013, p. 476).

Tal caracterização aparece num trabalho posterior, que trata dos afrescos astrológicos de Ferrara. De 1910 em diante, o que se observa é em grande medida uma acentuação das tendências que indiquei: a análise warburguiana amplia ainda mais seu alcance, passando agora pela recepção oriental da tradição legada pela

\footnotetext{
${ }^{12} \mathrm{~A}$ passagem seguinte dá uma ideia do que motiva Warburg a tratar dos tapetes decorativos, a que ele se refere como os "antepassados da arte da impressão": "a natureza do tapete tecido, o arazzo, não se baseava no ato criativo singular, já que o tecelão, como mediador anônimo da imagem, tecnicamente podia reproduzir o mesmo objeto tantas vezes quantas o comitente exigia; além do mais, o tapete não ficava afixado permanentemente à parede como um afresco; antes, era um veículo móvel de imagens." (Warburg, 2013, p. 289).

${ }^{13}$ Tradução cotejada com o original e alterada.
} 
Antiguidade greco-romana. Como resultado, temos uma interpretação ainda mais abrangente da cultura europeia como um todo, via de regra conduzida pela exposição do caminho percorrido e das mudanças sofridas por certa imagem-chave vinda da tradição cultural da Antiguidade (no estilo daquela passagem em que Warburg trata da metamorfose do Apolo do terceiro intermezzo no Apolo da Daphne).

Essa ampliação territorial tem consequências visíveis para a interpretação warburguiana da cultura europeia, pois permite conceber fenômenos bem localizados como pontos de passagem de um processo mais abrangente de desenvolvimento estilístico. Assim, nas passagens finais do estudo sobre os afrescos do $P a$ lazzo Schifanoia, a Vênus de Botticelli, antes referida sobretudo ao contexto mais imediato da cultura florentina, é reinterpretada como uma espécie de elo entre a Vênus de um dos afrescos pintados por Cossa em Ferrara e a de Rafael na Villa Farnesina, pois "Botticelli também teve que primeiro libertar sua deusa da beleza do realismo medieval da arte de gênero banal 'à francesa', da subserviência ilustrativa e da prática astrológica" ${ }^{14}$ (Ibid., p. 474). Ou seja: ao expor as transformações sucessivas sofridas pela imagem de Vênus, Warburg refaz, em linhas gerais, o traçado de um processo de desenvolvimento estilístico que compreende e alimenta o contexto mais imediato da criação das obras por ele tratadas.

Interpretações como essa são uma espécie de derivação de seu método histórico, marcado por uma forte pretensão científica - e Warburg realmente teve em vista uma ciência da cultura, como o subtítulo do volume deixa claro. Por isso mesmo, seus textos mais trabalhados trazem uma preocupação intensa e constante

${ }^{14}$ Tradução adaptada, após cotejo com o original. 
em mostrar que as relações que Warburg aponta entre duas imagens, ou entre uma imagem e um texto, não estavam baseadas numa semelhança superficial ou aparente. Assim, Warburg enfatiza que Poliziano de fato conhecia os poemas em que Ovídio retratava a movimentação dos trajes femininos nesta ou naquela cena de perseguição erótica, ou que Pellegrino Prisciani, o inspirador dos afrescos de Ferrara (executados uns por Francesco Cossa, outros por Cosimo Tura), conhecia as três fontes antigas que, como ele mostra, foram utilizadas para a composição da série - e assim por diante. É como se Warburg quisesse mostrar que o desenvolvimento estilístico "não dá saltos", ou seja: que, apesar de multifacetado e repleto de ramificações, possui certa continuidade, que poderia, pelo menos a princípio, ser demonstrada passo a passo. Como o próprio Warburg apreciava Darwin (em especial o trabalho sobre as expressões humanas) ${ }^{15}$, não me parece temerário ampliar a analogia mais um pouco: pois enquanto Darwin precisava livrar-se da ideia, ainda bastante aceita no seu tempo, de que as espécies correspondiam a atos singulares de um criador divino, Warburg confrontava tanto a historiografia estetizante da arte como o "diletantismo reverenciador de heróis"16 (Warburg, 2013, p. 440), com sua tendência a reduzir a obra à vontade do gênio criativo. O foco nas relações entre pintor e o patrono da obra, não raro mediadas pela figura do inspirador erudito, é claramente uma resposta crítica a tais tendências. Mas isso não significa que a agência do artista seja simplesmente tragada pela referência ao contexto; antes, sua contribuição individual é concebida como "energia de

\footnotetext{
${ }^{15}$ Ver Charles Darwin, A expressão das emoções nos homens e nos animais, tradução Leon de Souza Lobo Garcia, $2^{\text {a }}$ edição, São Paulo: Companhia das Letras, 2013.

${ }^{16}$ Tradução adaptada.
} 
confrontação" que precisa se haver com a tradição antiga - tal como assimilada no contexto presente e em função dos dilemas do momento -, ora subordinando-se a ela, ora resistindo ${ }^{17}$.

No notável estudo sobre a profecia na época da Reforma alemã, publicado em 1920, a interpretação warburguiana da cultura europeia chega a uma altura realmente antropológica. Warburg aí se serve da análise de uma série de cartas, horóscopos e gravuras ligadas aos círculos criados em torno de Lutero para tratar da infiltração do pensamento mágico à antiga no imaginário da Reforma - o que Warburg concebe como uma contribuição para a "história trágica da liberdade de pensamento do europeu moderno"18 (Ibid., p. 567), ou seja, a história da conquista do que ele chama de espaço de reflexão.

$$
* * *
$$

O texto sobre Lutero é o último trabalho mais profundo de Warburg contido n'A renovação da Antiguidade pagã ${ }^{19}$. Em 1921, Warburg se internaria no sanatório de Bellevue, na Suíça, para tratar de uma doença que o atormentava já há algum

${ }^{17}$ Cf., p. ex., Warburg, 2013, pp. 52-53, em que essas duas tendências contraditórias são detectadas na obra de Botticelli. A mesma ideia geral pode ser encontrada no texto sobre os afrescos de Schifanoia, mas aqui num registro um pouco diferente. Pois, nesse caso, Warburg sugere que os afrescos feitos por Cossa ofereceriam uma maior resistência ao "servilismo ilustrativo" vindo da arte medieval do que os de Tura (Ibid., pp. 470-471) ainda que "também a Vênus de Cossa não estivesse preparada para ascender das regiões inferiores dos trajes realistas 'à francesa' ao éter luminoso da 'Venere Aviática' [de Rafael]" (Ibid., p. 474; tradução adaptada).

${ }^{18}$ Tradução adaptada.

${ }^{19} \mathrm{O}$ volume conta com quatro textos posteriores a esse, todos bem menos elaborados. Destes, destaco apenas "A astrologia orientalizante" (Warburg, 2013, op. cit., pp. 623-627), em que temos uma retomada breve, mas ainda assim densa, de vários temas anteriormente explorados por Warburg. 
tempo; permaneceu por lá até 1924, onde foi tratado por Louis Binswanger. Reabilitado, logo retomou suas pesquisas, mas nenhum de seus trabalhos mais densos conduzidos desde então chegou a ser publicado em vida. Dentre eles, destaca-se a montagem de imagens conhecida como Atlas Mnemosine ${ }^{20}$; uma palestra sobre a cultura Pueblo (comunidades nativas do sudoeste do continente norte-americano, que Warburg visitou), ministrada quando ainda estava internado; e uma pesquisa sobre Rembrandt - todos ausentes na coletânea em questão, a não ser pelas menções dos editores.

Tais aspectos da obra warburguiana, em especial o atlas de imagens e as palestras sobre os Pueblos, são tematizados tanto por Michaud como por Didi-Huberman, nos livros publicados pela Contraponto juntamente com o de Warburg. Além disso, o livro de Michaud traz como anexo dois textos de Warburg, um de 1923, mais substancial, intitulado "Recordações de uma viagem à terra dos pueblos"; e outro, "Projeto de viagem à América", de 1927, uma peça mais simples, que, no presente contexto, interessa apenas por registrar a vontade de Warburg em expandir o domínio de sua análise para o outro lado do Atlântico.

Warburg desistiria de tal projeto - mas já havia experimentado esse voo interpretativo em direção à América ao rememorar a viagem que para lá fizera em meados da década de 1890. Nessa época, aproveitou sua estadia nos Estados Unidos para realizar uma espécie de aventura antropológica, que teve um impacto considerável, embora silencioso, em sua trajetória intelectual. O texto anexado ao livro de Michaud é composto por uma série

\footnotetext{
${ }^{20}$ Esse projeto, iniciado em 1924 , leva ao extremo o método de perseguir a trajetória das imagens. O atlas consiste basicamente numa série de painéis em que Warburg arranjava várias imagens de algum modo relacionadas entre si.
} 
de anotações e materiais para uma palestra que ele ministraria quase três décadas depois, no sanatório de Bellevue, como parte de seu processo de reabilitação.

"Recordações..." é um texto problemático em muitos sentidos, a começar pelo fato de não estar de modo algum pronto para publicação - não tem estrutura argumentativa, e alguns dos trechos não passam de anotações vagas. O próprio Warburg descreve-o como a "confissão de um esquizoide incurável"21, e insta que jamais seja publicado. Isso não é de espantar, já que Warburg estava ciente de que a sua compreensão da cultura Pueblo era limitada por muitas barreiras: não só se baseava em memórias de uma viagem já distante, como referia-se a uma comunidade que falava um idioma que ele não compreendia.

Como no texto sobre Lutero, aqui também o interesse antropológico incide na relação entre o pensamento mágico e o científico, entre o mito e o logos, entre o homem que apanha a "causa mágica" com as próprias mãos, para assim extorquir da natureza o efeito desejado, e o que a toma pela imaginação conceitual (Cf. Michaud, 2013, pp. 276-277). É nessa chave que Warburg interpreta a chamada dança da serpente, realizada como parte das celebrações sazonais em algumas das aldeias Pueblo: ao encenar sua captura e ao executar uma dança com serpentes vivas, o nativo buscaria granjear o favor da chuva ${ }^{22}$, necessária para o

\footnotetext{
${ }^{21}$ Cf. o texto de Warburg em Phillipe-Alain Michaud, 2013, Warburg e a imagem em movimento. Contraponto: Rio de Janeiro, p. 251 et seq. (a passagem citada está na p. 254).

${ }^{22} \mathrm{~A}$ serpente era associada ao raio no imaginário dos Pueblos, e raio, às chuvas. Nesse texto, Warburg relata, de modo fragmentário, alguns elementos da cultura Pueblo. Desses relatos, destaca-se a descrição de uma de suas danças cerimoniais, presenciada por Warburg, bem como a do mito acerca da origem do clã da serpente, narrada com base na literatura antropológica de que ele dispunha (Ibid., p. 279 et seq). Esta
} 
êxito da colheita.

Deve-se destacar que a interpretação de Warburg acerca da cultura Pueblo assenta-se numa série de pressupostos questionáveis para os padrões da etnologia moderna, dos quais o mais notável é a oposição entre uma humanidade "primitiva" e outra "civilizada". Diga-se que Warburg mostra certo desconforto com esse par conceitual: mais de uma vez, põe entre aspas termos como "primitivo" e "selvagem", e procura mostrar, por meio de comparações, que o pensamento chamado primitivo estaria ele mesmo presente na chamada civilização - uma resposta típica de quem já começava a questionar tais noções, mas ainda carecia de uma alternativa robusta o bastante para contorná-las. Mesmo assim, fica claro que, enquanto Warburg recorre ao atributo da civilização para se referir a um complexo cultural bem definido em termos territoriais - a tradição de raiz europeia -, o atributo "primitivo" não passa de um rótulo que agrega uma série de complexos culturais cuja única relação efetiva é o pertencimento à espécie humana: uma relação vaga demais para os padrões de Warburg. Cremos que esse seja um reflexo não só das noções que ele toma de empréstimo dos autores em que se apoiava, como Tito Vignoli, como também da desproporção entre o seu amplo e nuançado conhecimento sobre a cultura europeia e seu conhecimento bem mais restrito sobre outros sistemas culturais. Por isso tudo, tais recordações de Warburg devem ser lidas com cautela: sua compulsão dionísica em estabelecer associações não é aqui compensada pelo rígido controle apolínio que marca, ao lado daquele impulso, sua obra publicada e seu projeto de uma

última descrição é, na realidade, uma tradução resumida do mito tal como registrado em Jesse Walter Fewkes, 1894, "The Snake Ceremonials at Walpi", em: A Journal of American Ethnology and Archeology, Boston Nova Iorque: v. 4 , pp. $106-124$. 
ciência da cultura - mas por isso mesmo, esse me parece um texto especialmente interessante para uma compreensão mais profunda e crítica do próprio método warburguiano.

Seja como for, a publicação em português dos escritos de Warburg é digna de elogios, pois facilita enormemente o acesso do público brasileiro a essa interpretação do Renascimento europeu tão influente, tão rica em nuances e tão coesa, que abre espaço para uma leitura antropológica e para o diálogo interdisciplinar, evitando entrincheirar-se num esteticismo vazio. Do ponto de vista do método, a maior parte dos textos é exemplar, na medida em que consegue resolver bem a difícil equação entre elementos internos e externos da obra, sem cair nem num reducionismo esteticista, nem num sociologismo que passa por cima do conteúdo da obra e simplesmente o deduz de seus condicionantes sociais; temas difíceis e escorregadios como a astrologia também são tratados com o devido cuidado, de forma crítica e bem embasada abrindo espaço, aliás, para uma discussão sobre a influência da pensamento oriental sobre a cultura ocidental. Por isso tudo, espera-se que a obra seja bem recebida em terras brasileiras e gere frutos por aqui - agora que enfim está munida dos meios técnicos de que carecia para circular mais à vontade entre nós. 